\title{
Increased GFAP concentrations in the cerebrospinal fluid of patients with unipolar depression
}

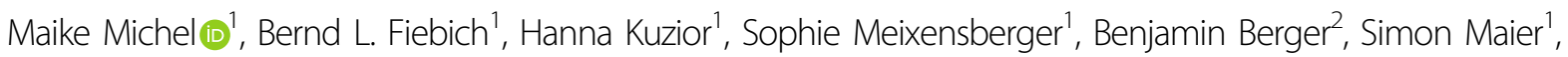 \\ Kathrin Nickel', Kimon Runge ${ }^{1}$, Dominik Denzel', Benjamin Pankratz' ${ }^{1}$ Miriam A. Schiele ${ }^{1}$, Katharina Domschke ${ }^{1,3}$, \\ Ludger Tebartz van Elst ${ }^{1}$ and Dominique Endres (iD)
}

\begin{abstract}
Inflammatory processes involving altered microglial activity may play a relevant role in the pathophysiology of depressive disorders. Glial fibrillary acidic protein (GFAP) and calcium-binding protein S100B are considered microglial markers. To date, their role has been studied in the serum and tissue material of patients with unipolar depression but not in the cerebrospinal fluid (CSF). Therefore, the aim of the current study was to examine GFAP and S100B levels in the CSF of patients with major depression to better understand their role in affective disorders. In this retrospective study, 102 patients with unipolar depression and 39 mentally healthy controls with idiopathic intracranial hypertension were investigated. GFAP and S100B levels were measured using commercially available ELISA kits. CSF routine parameters were collected during routine clinical care. The mean values of GFAP and S100B were compared using age (and sex) corrected ANOVAs. Matched subgroups were analyzed by using an independent sample $t$-test. In addition, correlation analyses between GFAP/S100B levels and CSF routine parameters were performed within the patient group. Patients with unipolar depression had significantly higher levels of GFAP than controls $(733.22 \mathrm{pg} / \mathrm{ml} \mathrm{vs} .245 .56 \mathrm{pg} / \mathrm{ml}, p<0.001)$. These results remained significant in a sub-analysis in which all controls were compared with patients suffering from depression matched 1:1 by age and sex $(632.26 \mathrm{pg} / \mathrm{ml} \mathrm{vs} .245 .56 \mathrm{pg} / \mathrm{ml}, p<0.001)$. Levels of S100B did not differ significantly between patients and controls $(1.06 \mathrm{ng} / \mathrm{ml}$ vs. $1.17 \mathrm{ng} / \mathrm{ml}, p=0.385)$. GFAP levels correlated positively with albumin quotients $(p<$ $0.050)$, S100B levels correlated positively with white blood cell counts $(p=0.001)$, total protein concentrations $(p<0.001)$, and albumin quotients $(p=0.001)$ in the CSF. The significance of the study is limited by its retrospective and open design, methodological aspects, and the control group with idiopathic intracranial hypertension. In conclusion, higher GFAP levels in patients with depression may be indicative of altered microglia activity, especially in astrocytes, in patients with unipolar depression. In addition, correlation analyses support the idea that S100B levels could be related to the integrity of the blood-brain/CSF barrier. Further multimodal and longitudinal studies are necessary to validate these findings and clarify the underlying biological processes.
\end{abstract}

\footnotetext{
Correspondence: Maike Michel (maike.michel@uniklinik-freiburg.de) or Ludger Tebartzvan Elst (tebartzvanelst@uniklinik-freiburg.de) or

Dominique Endres (dominique.endres@uniklinik-freiburg.de)

'Department of Psychiatry and Psychotherapy, Medical Center-University of Freiburg, Faculty of Medicine, University of Freiburg, 79104 Freiburg, Germany ${ }^{2}$ Clinic of Neurology and Neurophysiology, Medical Center-University of Freiburg, Faculty of Medicine, University of Freiburg, 79106 Freiburg, Germany Full list of author information is available at the end of the article

These authors contributed equally: Ludger Tebartz van Elst, Dominique Endres
}

\section{Introduction}

With a lifetime prevalence of more than $10 \%$, depression is among the most common mental disorders, thereby imposing a substantial personal, economic, and societal burden ${ }^{1}$. The most common pathophysiological explanation of depression relies on the monoamine hypothesis, which relates depressive symptoms to a lack of neurotransmitters such as serotonin, increased

\section{(-) The Author(s) 2021}

\footnotetext{
(c) Open Access This article is licensed under a Creative Commons Attribution 4.0 International License, which permits use, sharing, adaptation, distribution and reproduction c. in any medium or format, as long as you give appropriate credit to the original author(s) and the source, provide a link to the Creative Commons license, and indicate if changes were made. The images or other third party material in this article are included in the article's Creative Commons license, unless indicated otherwise in a credit line to the material. If material is not included in the article's Creative Commons license and your intended use is not permitted by statutory regulation or exceeds the permitted use, you will need to obtain permission directly from the copyright holder. To view a copy of this license, visit http://creativecommons.org/licenses/by/4.0/.
} 
degradation of monoamines, or impaired monoamine sensing ${ }^{2}$. However, in recent years, an increasing number of studies have suggested that inflammatory processes may also be responsible for depressive symptomatology ${ }^{3-10}$. As a result, the role of glial cells and their specific markers in body fluids have been investigated increasingly. The concentrations of glial fibrillary acidic protein (GFAP) in the cerebellum, prefrontal cortex, and anterior cingulate cortex have been found to be lower in patients with depression than in healthy controls ${ }^{11-13}$. In addition, decreased numbers of astrocytes have been found in hippocampal regions of patients with major depressive disorder ${ }^{14}$. Among other functions, GFAP is a crucial factor for an intact blood-brain barrier ${ }^{15}$. Moreover, proteins in the $\mathrm{S} 100$ protein family can influence inflammatory processes. They regulate a variety of cell types, such as astrocytes, lymphocytes, and smooth muscle cells ${ }^{16}$. Elevated serum concentrations of S100B have been found in patients with depression and may prove valuable for evaluating both diagnosis and treatment response ${ }^{17-23}$. Most studies that have examined these inflammatory markers in the context of major depression relied on serum or tissue samples. The concentration, origin, and role of inflammatory markers in the cerebrospinal fluid (CSF) of patients with depression have received considerably less attention in psychiatry (for an overview of previous studies see Table 1). However, CSF investigations are needed to better understand the potential role of these biomarkers in the central nervous system, as they can provide detailed insights into intrathecal processes.

\section{Rationale of this study}

The present study aimed to investigate the potential role of the microglial markers GFAP and S100B in the CSF of patients diagnosed with unipolar depression and compare their levels with those of a control group of participants with idiopathic intracranial hypertension (IIH, formerly termed pseudotumor cerebri). Furthermore, the correlative relationship of GFAP/S100B with CSF routine parameters was investigated.

\section{Participants and methods}

The study was part of a larger retrospective project that was approved by the local ethics committee (Faculty of Medicine, University of Freiburg, vote no. EK-Fr 609/14). Lumbar punctures were performed after carefully gathering information and after obtaining written informed consent either as a part of routine clinical care to rule out organic causes of depressive syndromes or-regarding the control group-as a diagnostic investigation or treatment approach for IIH.

\section{Study sample}

In this study, consecutive patients diagnosed with unipolar depression $(N=102)$ were compared to controls with IIH $(N=39)$. Only patients aged from 18 to 65 years were included. Patients diagnosed with unipolar depressive syndromes were treated as inpatients at the Department of Psychiatry and Psychotherapy, University of Freiburg. They were diagnosed by experienced professional psychiatrists based on the criteria in the International Statistical Classification of Diseases and Related Health Problems, 10th revision. Patients diagnosed with schizophrenia, bipolar disorder, or underlying dementia were excluded. Previous neurological illnesses were not a fundamental exclusion criterion, but only patients who received a lumbar puncture during inpatient psychiatric treatment to clarify the depressive syndrome were included. The control group has already been described in previous studies ${ }^{10,24}$. Control subjects were also between 18 and 65 years old, and they additionally had to be free of any psychiatric diagnosis and not have taken psychotropic medication. No matching between patients and controls regarding sex or age was performed for the whole cohort of study participants (for details see Table 2). However, for a sub-analysis, an optimal 1:1 matching (https://cran.rproject.org/web/packages/MatchIt/MatchIt.pdf) by age and sex was implemented using the MatchIt package ${ }^{25}$ in $R^{26}$, which accesses functions from the optmatch package $^{27}$. Thus, the calculations were performed using logistic regression (distances as propensity scores). From 134 study participants (96 patients and 38 controls) with available GFAP findings, 38 optimal matching patients were assigned to the 38 control subjects (total $N=76$ ).

\section{Cerebrospinal fluid analysis and instrumental diagnostics}

The routine CSF analysis included the determination of the following dimensional values (used for correlation analyses): white blood cell (WBC) count, protein concentration, albumin quotient (AQ), and immunoglobulin (Ig)G index. The measuring was performed according to an established methodology ${ }^{7,8,28}$. The routine analyses were carried out in the CSF laboratory, Department of Neurology and Neurophysiology, University of Freiburg (https://www.uniklinik-freiburg.de/ neurologie/klinik/diagnostische-einrichtungen/liquorlabor.html). The residual CSF material was then deepfrozen at $-80^{\circ} \mathrm{C}$. Only patients and controls with sufficient residual material were included for GFAP and S100B analyses. The mean storage period of the CSF material was $3.60 \pm 2.86$ years for the patient group and $3.53 \pm 2.33$ years for the control group. Therefore, the mean storage time did not differ significantly between the groups $(T=0.149 ; p=0.882)$. 
Table 1 Overview of selected clinical studies investigating GFAP and S100B in cerebrospinal fluid.

\begin{tabular}{|c|c|c|}
\hline $\begin{array}{l}\text { Study (by } \\
\text { publication year) }\end{array}$ & Patients/controls & Results related to GFAP and $\mathrm{S} 100$ \\
\hline \multicolumn{3}{|c|}{ Studies comprising patients with affective disorders } \\
\hline 61 & 9 patients with MDD undergoing ECT & S100B was not changed by clinically successful ECT \\
\hline \multirow[t]{2}{*}{33} & 65 elderly women without MDD, 13 with MDD & - GFAP in CSF was not related to depression \\
\hline & & $\begin{array}{l}\text { - Women developing dementia within } 10 \text { years had increased levels } \\
\text { of GFAP in CSF }\end{array}$ \\
\hline \multirow[t]{2}{*}{35} & 133 patients with $\mathrm{BD}$ and 86 healthy controls & - No difference of S100B levels in CSF between controls and patients \\
\hline & & $\begin{array}{l}\text { - No correlations between S100B in CSF and clinical variables or } \\
\text { medication }\end{array}$ \\
\hline 34 & 31 patients with MDD and 32 healthy controls & $\begin{array}{l}\text { Levels of S100B in CSF did not differ between MDD patients and } \\
\text { healthy controls }\end{array}$ \\
\hline 36 & $\begin{array}{l}\text { Japanese cohort of } 94 \text { patients with } \\
\text { schizophrenia, } 68 \text { with BD, } 104 \text { with MDD and } 118\end{array}$ & $\begin{array}{l}\text { - S100B in CSF was positively correlated with Hamilton sleep } \\
\text { subscale in MDD }\end{array}$ \\
\hline & healthy controls & $\begin{array}{l}\text { - S100B in CSF was positively correlated with symptom severity in } \\
\text { schizophrenia }\end{array}$ \\
\hline \multicolumn{3}{|c|}{ Studies analyzing patients with different non-affective disorders } \\
\hline 62 & 22 asphyxiated and 8 non-asphyxiated newborns & S100 in CSF correlated positively with indicators for poor prognosis \\
\hline \multirow[t]{2}{*}{63} & 12 patients with schizophrenia and 17 controls & - Higher levels of S100B in CSF and serum in the schizophrenia group \\
\hline & & - No differences in GFAP concentrations \\
\hline 64 & $\begin{array}{l}40 \text { consecutive patients with non-inflammatory } \\
\text { neurological disorders }\end{array}$ & $\begin{array}{l}\text { S100B in CSF was negatively correlated with severity of depressive } \\
\text { symptoms in BDI-II questionnaire }\end{array}$ \\
\hline 65 & $\begin{array}{l}24 \text { patients with varicella zoster infection of the } \\
\text { central nervous system and } 14 \text { controls }\end{array}$ & $\begin{array}{l}\text { GFAP levels in CSF were elevated in patients with encephalitis } \\
\text { compared to controls }\end{array}$ \\
\hline 66 & 94 patients with $A D$ and 39 controls & $\begin{array}{l}\text { GFAP was not associated with } A \beta \text { peptides, but increased with age } \\
\text { in controls }\end{array}$ \\
\hline 67 & $\begin{array}{l}23 \text { patients with PD undergoing deep brain } \\
\text { stimulation of the subthalamic nucleus }\end{array}$ & $\begin{array}{l}\text { GFAP concentrations in CSF increased shortly after surgery, but } \\
\text { normalized after few months and remained normal over more than } \\
\text { a decade afterwards }\end{array}$ \\
\hline 68 & 49 patients with primary Sjögren's syndrome & In PCA, S100B dominated a component related to fatigue. \\
\hline 69 & $\begin{array}{l}90 \text { patients with neurological symptoms without } \\
\text { neurological diagnosis }\end{array}$ & GFAP did not indicate signs of neuronal or astroglial damage \\
\hline 70 & $\begin{array}{l}39 \text { patients with NMOSD, } 69 \text { with MS, } 5 \text { with optic } \\
\text { neuritis and } 37 \text { controls }\end{array}$ & $\begin{array}{l}\text { GFAP levels in CSF were elevated in patients with NMOSD and } \\
\text { antibodies against aquaporin } 4 \text { compared to controls }\end{array}$ \\
\hline
\end{tabular}

$A D$ Alzheimer's disease, $B D$ bipolar disorder, $E C T$ electroconvulsive therapy, $M D D$ major depressive disorder, $M S$ multiple sclerosis, NMOSD neuromyelitis optica spectrum disorder, PCA principal component analysis, PD Parkinson's disease.

\section{Measurement of GFAP and S100B}

GFAP measurements were performed using commercially available high-sensitivity ELISA kits from Aviscera Bioscience (Santa Clara, USA), and S100B analyses were performed using high-sensitivity ELISA kits from CloudClone Corp. (Houston, TX, USA). The ELISA kits were used in accordance with the manufacturer's specifications, with the exception of using CSF samples. Both kits have not yet been validated for CSF testing.

\section{Data handling and statistical analyses}

Statistical analyses were performed using Statistical Package for the Social Sciences, version 25 (IBM Corp., Armonk, NY). Age and GFAP levels (only for age and sex matched subgroups) were compared using independent sample $t$-tests, differences in sex ratio were calculated with $\chi^{2}$. Univariate ANOVAs with age as a covariate were performed for comparison of S100B and GFAP. In a post hoc analysis, we added univariate 
Table 2 Clinical data of patients and controls.

\begin{tabular}{|c|c|c|c|}
\hline & $\begin{array}{l}\text { Patients } \\
(N=102)\end{array}$ & $\begin{array}{l}\text { Controls } \\
(N=39)\end{array}$ & Statistics \\
\hline Sex & $47 \mathrm{M}: 55 \mathrm{~F}$ & $6 \mathrm{M}: 33 \mathrm{~F}$ & $p=0.001$ \\
\hline Mean age (age range) & $\begin{array}{l}44.25 \pm 13.63 \\
(18-65 \text { years })\end{array}$ & $\begin{array}{l}34.62 \pm 12.03 \\
(18-61 \text { years })\end{array}$ & $p<0.001$ \\
\hline \multicolumn{4}{|l|}{ Diagnosis } \\
\hline $\begin{array}{l}\text { Depressive episode with } \\
\text { psychotic symptoms }\end{array}$ & 19/102 (19\%) & - & \\
\hline $\begin{array}{l}\text { Depressive episode without } \\
\text { psychotic symptoms }\end{array}$ & $83 / 102(81 \%)$ & - & \\
\hline \multicolumn{4}{|l|}{ Severity of depression } \\
\hline Mild & 0/102 (0\%) & - & \\
\hline Moderate & $5 / 102(5 \%)$ & - & \\
\hline Severe & 97/102 (95\%) & - & \\
\hline \multicolumn{4}{|l|}{ Course of disease } \\
\hline Recurrent/chronic & 77/102 (75\%) & - & \\
\hline First episode & $25 / 102(25 \%)$ & - & \\
\hline \multicolumn{4}{|l|}{ Neurological comorbidity } \\
\hline Neurovascular & $n=1(1 \%)$ & - & \\
\hline Traumatic & $n=1(1 \%)$ & - & \\
\hline Polyneuropathy & $n=1(1 \%)$ & - & \\
\hline Migraine/Headache & $n=7(7 \%)$ & - & \\
\hline Restless-leg's Syndrome & $n=3(3 \%)$ & - & \\
\hline Vertigo & $n=2(2 \%)$ & - & \\
\hline Overall & $n=15(15 \%)$ & - & \\
\hline \multicolumn{4}{|l|}{$\begin{array}{l}\text { Psychotropic drugs at the time } \\
\text { of sampling }\end{array}$} \\
\hline Medicated & $n=99(97 \%)$ & - & \\
\hline Unmedicated & $n=3(3 \%)$ & - & \\
\hline
\end{tabular}

CSF cerebrospinal fluid, MRI magnetic resonance imaging, EEG electroencephalography, $F$ female, $M$ male, SSRI selective serotonin reuptake inhibitor, SSNRI selective serotonin/noradrenaline reuptake inhibitor.

Bold values indicates statistically significant results.

ANOVAs with age and sex correction for comparison of S100B and GFAP concentrations. Levels of routine CSF parameters (WBC count, total protein, $\mathrm{AQ}$, IgG index) were analyzed using univariate ANOVAs with age and sex correction. S100B and GFAP concentrations were correlated with routine CSF parameters (WBC count, total protein, AQ, IgG index) and different clinical/ psychometric scores (suicide attempts, number of earlier inpatient stays, Clinical Global Impression (CGI) score, Global Assessment of Functioning (GAF) score, and psychopathological scores following the German Association for Methodology and Documentation in Psychiatry (AMDP scores)) in the patient group using Pearson correlation coefficients. Significance was set to $p$ values of $<0.05$. Given the exploratory approach, no correction for multiple testing was performed.

\section{Results}

\section{Sociodemographic and clinical data}

Tables 2 and 3 summarize the sociodemographic and clinical data of the study group. The sex distribution differed significantly between patients and controls $(p=$ 0.001 ), with $54 \%$ of patients and $85 \%$ of controls being female. Likewise, a significant difference in age was found between patients and controls $(p<0.001)$. Most patients (75\%) experienced a recurrent or chronic depressive episode, and $25 \%$ of patients had experienced their first episode. Five patients had moderate depression $(5 \%)$ and 97 patients (95\%) had severe depression. A total of 99 patients (97\%) received psychotropic medication. Neurologic comorbidities occurred in $15 \%$ of patients.

\section{GFAP/S100B findings}

The concentrations of GFAP and S100B in CSF are presented in Table 4. In ANOVAs corrected for age, S100B levels did not differ significantly between patients and controls, yet patients with unipolar depression had a significantly higher concentration of GFAP than controls. In a post hoc analysis with additional correction for sex, the results regarding GFAP concentrations remained significant $(F=31.057, p<0.001)$, and S100B levels still showed no significant differences between the groups $(F=1.531, p=0.218)$. When comparing all controls $(N=$ 38 ) with available GFAP results and a matched group of patients with depression $(N=38)$, differences in age (patient group: $36.18 \pm 12.97$ years; controls: $34.84 \pm 12.11$ years; $T=0.466 ; p=0.642$ ) and sex (patients: five males and 33 females; controls: six males and 32 females; $\mathrm{Chi}^{2}=0.106, p=0.744$ ) were no longer evident. The differences in GFAP levels between patients suffering from depression $(632.26 \pm 309.18)$ and controls $(245.56 \pm$ $176.25)$ remained highly significant $(T=6.698, p<0.001)$.

\section{Basic CSF findings and instrumental diagnostics}

The routine CSF findings are presented in Table 5. The mean total protein concentration and AQ levels were significantly higher in patients than in controls. There were no significant differences in WBC counts and IgG indices.

\section{Correlation analyses}

S100B levels in the group of patients with unipolar depression correlated positively with WBC count ( $r=$ $0.323, p=0.001)$, total protein $(r=0.359, p<0.001)$, and AQs $(r=0.327, p=0.001)$. GFAP levels in the patient group correlated positively with AQs $(r=0.201, p<$ $0.050)$. No significant correlations between S100B or GFAP levels and suicide attempts, number of earlier inpatient stays, CGI, GAF, or AMDP scores were detected.

\section{Discussion}

The main finding of the current study was that the GFAP concentration in the CSF was significantly higher in patients with unipolar depression than in controls with 
Table 3 Characterization of the patient group.

\begin{tabular}{|c|c|}
\hline & $\begin{array}{l}\text { Patients with unipolar depression } \\
(N=102)\end{array}$ \\
\hline \multicolumn{2}{|l|}{ Marital status } \\
\hline Single & 48 (47\%) \\
\hline Married & $36(35 \%)$ \\
\hline Divorced & $12(12 \%)$ \\
\hline Widowed & $5(5 \%)$ \\
\hline Unknown & $1(1 \%)$ \\
\hline \multicolumn{2}{|l|}{ Level of education } \\
\hline Low & $21(21 \%)$ \\
\hline Middle & $20(20 \%)$ \\
\hline High & $55(54 \%)$ \\
\hline Other & $1(1 \%)$ \\
\hline Unknown & $5(5 \%)$ \\
\hline \multicolumn{2}{|l|}{ Work situation } \\
\hline Unemployed & $9(9 \%)$ \\
\hline Others not working & $5(5 \%)$ \\
\hline Working & $53(52 \%)$ \\
\hline In training & $14(14 \%)$ \\
\hline Retired & $18(18 \%)$ \\
\hline Housewife/-man & $3(3 \%)$ \\
\hline \multicolumn{2}{|l|}{ Housing situation } \\
\hline Alone & $43(42 \%)$ \\
\hline With partner/family & $46(45 \%)$ \\
\hline With parents/guardian & $11(11 \%)$ \\
\hline Other & $1(1 \%)$ \\
\hline Unknown & $1(1 \%)$ \\
\hline
\end{tabular}

IIH. In addition, a positive correlation between S100B levels and established blood-brain/CSF barrier parameters (AQ and protein concentration) was found in the patient group.

\section{The present findings in the context of earlier studies}

GFAP levels are known to be altered in brain damagefor example, as a result of traumatic injuries or in the course of neurodegenerative or neuroinflammatory processes $^{29,30}$. GFAP may also be involved in long-term potentiation $^{31}$. So far, only few studies have investigated the concentrations of GFAP in the CSF of patients with major depression ${ }^{32}$. In the only other comparable study, GFAP in CSF was not found to be related to major depression in elderly women ${ }^{33}$. However, in contrast to the current study, this was a much older patient group,
Table 4 S100B and GFAP concentrations in both study groups.

\begin{tabular}{llll}
\hline & Patients $(\boldsymbol{N}=\mathbf{1 0 2})$ & Controls $(\boldsymbol{N}=\mathbf{3 9})$ & Statistics \\
\hline GFAP pg/ml & $733.22 \mathrm{pg} / \mathrm{ml} \pm$ & $245.56 \mathrm{pg} / \mathrm{ml} \pm$ & $F=41.380$ \\
$($ Mean \pm SD $)$ & $401.42 \mathrm{pg} / \mathrm{ml}$ & $176.25 \mathrm{pg} / \mathrm{ml}$ & $\boldsymbol{p}<\mathbf{0 . 0 0 1}$ \\
& $(N=96)^{\mathrm{a}}$ & $(N=38)^{\mathrm{a}}$ & \\
S100B ng/ml & $1.06 \mathrm{ng} / \mathrm{ml} \pm$ & $1.17 \mathrm{ng} / \mathrm{ml} \pm$ & $F=0.759$ \\
$($ Mean \pm SD $)$ & $0.88 \mathrm{ng} / \mathrm{ml}$ & $1.08 \mathrm{ng} / \mathrm{ml}$ & $p=0.385$ \\
& $(N=100)^{\mathrm{a}}$ & & \\
\hline
\end{tabular}

$S D$ standard deviation

${ }^{a} A$ total of 102 patients and 39 controls were studied. GFAP measurement was successful in 96 of the 102 patients and in 38 of 39 controls. S100B measurement was successful in 100 of the 102 patients. Bold values indicates statistically significant results.

which could possibly explain the differences to our study results (with higher GFAP levels). As outlined above, several other studies have found lower GFAP levels and decreased numbers of astrocytes in different cerebral regions of patients suffering from depression compared to healthy controls ${ }^{11-14}$. In contrast to the present investigation, these studies utilized postmortem tissue samples instead of CSF and may therefore not be directly comparable as CSF samples exclusively measure extracellular concentrations of GFAP, while in tissue samples, intracellular and membrane-bound proteins add to the signal intensity in concentration measurements. Moreover, secretion of GFAP into CSF with subsequent distribution in the whole CSF spaces may have a diluting effect regarding cerebral tissue and lead to a relative enrichment in CSF. Still, the discrepancy between elevated concentrations of GFAP in CSF and decreased GFAP levels in brain tissue samples needs to be further addressed, ideally in studies combining both analyses for the same patients.

The lack of a significant difference in the concentrations of S100B in CSF between patients and controls in the present study is in agreement with earlier findings in patients with major depression ${ }^{34}$ and bipolar disorder ${ }^{35}$. In a group of Japanese patients with major depression, S100B was positively correlated with the Hamilton sleep subscale $^{36}$, no similar correlation with the AMDP score for sleep dysfunction was detected in the present study. A meta-analysis of inflammatory biomarkers in the CSF of patients with mood disorders found that total protein, albumin, and AQs were higher in patients with mood disorders than in healthy controls ${ }^{37,38}$. The basic CSF findings from the current study indicating increased protein levels and AQs are in line with these previous results.

\section{Pathophysiological implications of the GFAP and S100B findings}

Pathologic changes in glial cells and glial metabolism have long been suspected to play a key role in major 
Table 5 Findings in cerebrospinal fluid routine diagnostics.

\begin{tabular}{|c|c|c|c|}
\hline & Patients $(N=102)$ & Controls $(N=39)$ & Statistics $^{\mathrm{a}}$ \\
\hline WBC count/ $\mu \mathrm{l}($ Mean \pm SD) & $2.08 \pm 3.53$ & $2.60 \pm 7.59(N=35)^{b}$ & $p=0.700$ \\
\hline Total protein in mg/l (Mean \pm SD) & $462.68 \pm 195.84$ & $309.33 \pm 142.53$ & $p=0.007$ \\
\hline Albumin quotient (Mean \pm SD) & $5.80 \pm 2.56$ & $3.93 \pm 1.81$ & $p<0.001$ \\
\hline IgG Index in mg/l (Mean \pm SD) & $0.49 \pm 0.08$ & $0.50 \pm 0.04$ & $p=0.540$ \\
\hline
\end{tabular}

WBC white blood cell, $S D$ standard deviation, $\lg G$ immunoglobulin $\mathrm{G}, O C B$ s oligoclonal bands.

${ }^{a}$ Corrected for age and sex.

${ }^{\mathrm{b}}$ One control patient suffered from self-limiting reactive pleocytosis.

Bold values indicates statistically significant results.

depression $^{21,39}$. GFAP is widely regarded as an established marker for astrocytic pathologies, and a decreased expression level of GFAP and reduced density of GFAPimmunoreactive astrocytes in tissue samples from various cerebral areas have been associated with major depres$\operatorname{sion}^{11,14,40-42}$. Additionally, there seems to be a difference in glial changes between early- and late-life depression, with rather subtle glial changes in elderly patients ${ }^{43,44}$. For the first time, the current study produces evidence of astrocytic pathology in major depression in terms of increased GFAP signals based on CSF measurements. In a recent prospective study comprising 12 patients with spinal cord injury, GFAP was found to be elevated in CSF possibly reflecting neuronal injury ${ }^{45}$. Accordingly, elevated levels of GFAP in CSF could also be a consequence of neuronal damage. Moreover, based on the current data, it is not possible to determine if GFAP is released by glial cells as part of a response to neuronal damage or if it is the result of glial cell loss. Further investigations are needed to connect the CSF findings to possible pathophysiological pathways that may precede GFAP release, such as the chronic mild stress response ${ }^{46}$.

Extensive studies on S100B in depression have been conducted in the last two decades. Elevated concentrations of S100B in serum samples have been associated with major depression, and a decrease in S100B in the course of therapy may be an indicator of therapy response, although the latter is under dispute ${ }^{17,18,21,39,47}$. The involvement of S100B would provide a link to inflammatory processes, as S100B can bind to the receptor for advanced glycation end-products, which is a known regulator of immunologic and inflammatory pathways ${ }^{48}$. In addition, in a rat model, chronic stress was found to influence S100B expression in tissue samples, thus yielding a possible connection between the stress response and depression ${ }^{49}$. In the current study, no significant difference in S100B levels in CSF was identified between patients with depression and controls. Therefore, the results of our study do not support the previously reported alterations in serum and animal models. However, the detected correlations between S100B levels and
AQs and protein levels support the long-held hypothesis that S100B levels could be markers for disrupted blood-brain/CSF function ${ }^{50}$.

\section{Clinical and research implications}

As only very limited data about the relation of GFAP in CSF to unipolar depression are currently available, this study can provide a starting point for further investigations. Given that GFAP is elevated in the CSF of patients with major depression, it may serve as an additional state or trait biomarker in depression. However, the results of previous studies to date tend to indicate a transdiagnostic phenomenon (see Table 1); thus, it is necessary to evaluate GFAP in patients with depression in combination with other alterations, such as altered cytokine levels ${ }^{10}$. Certainly, data indicating a possible role of GFAP in the pathogenesis or progression of major depression will add to the growing knowledge of the possible involvement of inflammatory processes in depression ${ }^{51,52}$. Based on our data, it is not clear if inflammatory processes are the cause of depression or if they occur as a secondary effect in patients with depression. Hence, future longitudinal studies involving CSF examinations, including the measurement of GFAP, in combination with additional immunological markers are necessary.

\section{Limitations}

Although a large number of patients underwent CSF examinations, the current study has some relevant limitations. Because of the retrospective nature of the study, only limited psychometric data were available. In addition, the study groups were not matched for age and sex. For age, a relevant influence has been reported in previous studies. Si et al. reported a decrease in GFAP levels in postmortem brain tissue with age in 15 patients with major depression and 15 controls $^{12}$. Therefore, age (as well as age and sex) corrected ANOVAs were performed in this study, and the results remained stable. Finally, for a subanalysis, 1:1 matching by age and sex was performed. Again, GFAP levels were identified to be significantly elevated in patients with unipolar depression compared with matched controls. Thus, the authors concluded that 
the age (and sex) differences alone did not sufficiently explain the group differences. The effects of other influencing factors, such as medication, psychiatric comorbidity, or body mass index, cannot be excluded ${ }^{53}$. Furthermore, the presence of neurological comorbidities within the group of patients may have a confounding influence on the results. In our department, lumbar punctures are only performed in severe cases with major depression to rule out organic forms. Therefore, the results are not generalizable to all patients with unipolar depression. Because of the invasive nature of lumbar punctures, healthy controls were not recruited for ethical reasons. Additionally, this study was intended as a hypothesis-generating investigation to serve as a potential starting point for further research on GFAP and S100B levels in CSF as potential biomarkers in unipolar depression, limiting the justification for a possible control group of healthy volunteers even further. Thus, given these restrictions, patients with IIH and without psychiatric comorbidities were used as a mentally healthy control group. This approach has been established in previous studies $^{10,24,28}$, but nevertheless, pathological processes in the IIH group may have influenced the results ${ }^{54}$. Preanalytical handling of the samples was primarily performed to assure measurement of the respective routine CSF parameters. Therefore, the samples were not deepfrozen directly after lumbar punctures, which would have been optimal ${ }^{55-57}$. However, at room temperature GFAP and $\mathrm{S100B}$ have been reported to be stable in CSF for up to $24 \mathrm{~h}$ (GFAP) and 2 days (S100B), respectively ${ }^{58-60}$. Storage time also did not differ between the patient and control group. Therefore, preanalytical effects are unlikely to have influenced the results.

\section{Conclusion}

This study is one of the first to measure S100B and GFAP in the CSF of patients with unipolar depression. Elevated GFAP levels were detected; therefore, GFAP levels may serve as an additional biomarker for major depression in the future, but further investigations, including multimodal longitudinal studies, are needed to clarify the exact role and reliability of intrathecal GFAP alterations in depression.

\footnotetext{
Acknowledgements

This work was supported by a grant from the Ministry of Science, Research and the Arts of Baden-Württemberg. The article processing charge was funded by the Baden-Wuerttemberg Ministry of Science, Research and Art and the University of Freiburg in the funding programme Open Access Publishing.
}

\footnotetext{
Author details

${ }^{1}$ Department of Psychiatry and Psychotherapy, Medical Center-University of Freiburg, Faculty of Medicine, University of Freiburg, 79104 Freiburg, Germany. ${ }^{2}$ Clinic of Neurology and Neurophysiology, Medical Center-University of Freiburg, Faculty of Medicine, University of Freiburg, 79106 Freiburg, Germany. ${ }^{3}$ Center for Basics in Neuromodulation, Faculty of Medicine, University of Freiburg, 79106 Freiburg, Germany
}

\section{Author contributions}

M.M., B.L.F., H.K., L.T.v.E., and D.E. created the study design. B.L.F., K.D., M.A.S., L.T. V.E., and D.E. supervised the study. H.K. and B.L.F. were responsible for laboratory measurements. B.B. performed CSF basic analyses. M.M., S.Me., and S.Ma. performed the statistical analyses. S.Ma. performed the 1:1 matching. M. M. wrote the paper and performed the data search. D.E. and L.T.v.E. critically revised the manuscript and contributed as shared last authors. K.N., K.R., D.D., B. P., M.A.S., and K.D. supported the interpretation and revised the manuscript further. All authors were critically involved in the theoretical discussion and composition of the manuscript. All authors read and approved the final version of the manuscript.

\section{Funding}

Open Access funding enabled and organized by Projekt DEAL.

\section{Conflict of interest}

B.B. received travel grants and/or training expenses from Bayer Vital GmbH, Ipsen Pharma GmbH, Norvartis, Biogen $\mathrm{GmbH}$, and Genzyme, as well as lecture fees from Ipsen Pharma GmbH, Alexion Pharma GmbH, Merck, Sanofi Genzyme, and Roche. K.D. is a member of the Steering Committee Neurosciences, Janssen. L.T.v.E. received compensation for advisory boards, lectures, or travel within the last 3 years from Roche, Eli Lilly, Janssen-Cilag, Novartis, Shire, UCB, GSK, Servier, Janssen, and Cyberonics. All other authors declare that they have no potential conflicts of interest.

\section{Publisher's note}

Springer Nature remains neutral with regard to jurisdictional claims in published maps and institutional affiliations.

Received: 11 February 2021 Revised: 26 March 2021 Accepted: 5 May 2021 Published online: 21 May 2021

\section{References}

1. Lim, G. Y. et al. Prevalence of depression in the community from 30 countries between 1994 and 2014. Sci. Rep. 8, 2861 (2018).

2. Elhwuegi, A. S. Central monoamines and their role in major depression. Prog. Neuropsychopharmacol. Biol. Psychiatry 28, 435-451 (2004).

3. Dantzer, R., O'Connor, J. C., Lawson, M. A. \& Kelley, K. W. Inflammationassociated depression: from serotonin to kynurenine. Psychoneuroendocrinology 36, 426-436 (2011).

4. Zunszain, P. A., Hepgul, N. \& Pariante, C. M. Inflammation and depression. Curr. Top. Behav. Neurosci. 14, 135-151 (2013).

5. Miller, A. H. \& Raison, C. L. The role of inflammation in depression: from evolutionary imperative to modern treatment target. Nat. Rev. Immunol. 16, 22-34 (2016).

6. Enache, D., Pariante, C. M. \& Mondelli, V. Markers of central inflammation in major depressive disorder: a systematic review and meta-analysis of studies examining cerebrospinal fluid, positron emission tomography and postmortem brain tissue. Brain Behav. Immun. 81, 24-40 (2019).

7. Endres, D. et al. Evidence of cerebrospinal fluid abnormalities in patients with depressive syndromes. J. Affect Disord. 198, 178-184 (2016).

8. Endres, D. et al. Cerebrospinal fluid, antineuronal autoantibody, EEG, and MRI findings from 992 patients with schizophreniform and affective psychosis. Transl. Psychiatry 10, 279 (2020).

9. Dersch, R. et al. Anti-thyroid peroxidase and anti-thyroglobulin autoantibodies in the cerebrospinal fluid of patients with unipolar depression. J. Clin. Med. 9, 2391 (2020).

10. Kuzior, H. et al. Increased IL-8 concentrations in the cerebrospinal fluid of patients with unipolar depression. Compr. Psychiatry 102, 152196 (2020).

11. Fatemi, S. H. et al. Glial fibrillary acidic protein is reduced in cerebellum of subjects with major depression, but not schizophrenia. Schizophr. Res. 69, 317-323 (2004).

12. Si, X., Miguel-Hidalgo, J. J., O'Dwyer, G., Stockmeier, C. A. \& Rajkowska, G. Agedependent reductions in the level of glial fibrillary acidic protein in the prefrontal cortex in major depression. Neuropsychopharmacology 29, 2088-2096 (2004). 
13. Webster, M. J., O'Grady, J., Kleinman, J. E. \& Weickert, C. S. Glial fibrillary acidic protein mRNA levels in the cingulate cortex of individuals with depression, bipolar disorder and schizophrenia. Neuroscience 133, 453-461 (2005).

14. Cobb, J. A. et al. Density of GFAP-immunoreactive astrocytes is decreased in left hippocampi in major depressive disorder. Neuroscience 316, 209-220 (2016).

15. Liedtke, W. et al. GFAP is necessary for the integrity of CNS white matter architecture and long-term maintenance of myelination. Neuron 17, 607-615 (1996).

16. Donato, R. et al. Functions of $\mathrm{S} 100$ proteins. Curr. Mol. Med. 13, 24-57 (2013).

17. Grabe, H. J., Ahrens, N., Rose, H. J., Kessler, C. \& Freyberger, H. J. Neurotrophic factor S100 beta in major depression. Neuropsychobiology 44, 88-90 (2001).

18. Schroeter, M. L., Abdul-Khaliq, H., Diefenbacher, A. \& Blasig, I. E. S100B is increased in mood disorders and may be reduced by antidepressive treatment. Neuroreport 13, 1675-1678 (2002).

19. Arolt, V. et al. S100B and response to treatment in major depression: a pilot study. Eur. Neuropsychopharmacol. 13, 235-239 (2003).

20. Arts, B. et al. S100 and impact of ECT on depression and cognition. J. ECT 22, 206-212 (2006)

21. Schroeter, M. L., Abdul-Khaliq, H., Krebs, M., Diefenbacher, A. \& Blasig, I. E. Serum markers support disease-specific glial pathology in major depression. J. Affect Disord. 111, 271-280 (2008).

22. Benitez, A. et al. Troponin and S100 beta are associated with depression in healthy older adults. Aging Ment. Health 13, 894-898 (2009).

23. Arora, P. et al. Serum S100B levels in patients with depression. Indian J. Psychiatry 61, 70-76 (2019).

24. Runge, $K$. et al. Cerebrospinal fluid findings of 36 adult patients with autism spectrum disorder. Brain Sci. 10, 355 (2020).

25. Ho, D. E., Imai, K., King, G. \& Stuart, E. A. Matchlt: nonparametric preprocessing for parametric causal inference. J. Stat. Soft. 42, 1-28 (2011).

26. $\mathrm{R}$ Core Team. R: A Language and Environment for Statistical Computing ( $\mathrm{R}$ Foundation for Statistical Computing, 2020).

27. Hansen, B. B. \& Klopfer, S. O. Optimal full matching and related designs via network flows. J. Comput. Graph. Stat. 15, 609-627 (2006).

28. Stich, O. et al. An observational study of inflammation in the central nervous system in patients with bipolar disorder. Bipolar Disord. 17, 291-302 (2015).

29. Middeldorp, J. \& Hol, E. M. GFAP in health and disease. Prog. Neurobiol. 93, 421-443 (2011)

30. Abdelhak, A. et al. Glial activation markers in CSF and serum from patients with primary progressive multiple sclerosis: potential of serum GFAP as disease severity marker? Front. Neurol. 10, 280 (2019).

31. Brenner, M. Role of GFAP in CNS injuries. Neurosci. Lett. 565, 7-13 (2014).

32. Al Shweiki, M. R. et al. Major depressive disorder: insight into candidate cerebrospinal fluid protein biomarkers from proteomics studies. Expert Rev. Proteom. 14, 499-514 (2017).

33. Gudmundsson, $\mathrm{P}$. et al. Is there a CSF biomarker profile related to depression in elderly women? Psychiatry Res. 176, 174-178 (2010).

34. Schmidt, F. M., Mergl, R., Stach, B., Jahn, I. \& Schönknecht, P. Elevated levels of cerebrospinal fluid neuron-specific enolase (NSE), but not S100B in major depressive disorder. World J. Biol. Psychiatry 16, 106-113 (2015).

35. Jakobsson, J. et al. Elevated concentrations of neurofilament light chain in the cerebrospinal fluid of bipolar disorder patients. Neuropsychopharmacology $\mathbf{3 9}$ 2349-2356 (2014).

36. Hidese, S. et al. Cerebrospinal fluid neuroplasticity-associated protein levels in patients with psychiatric disorders: a multiplex immunoassay study. Transl. Psychiatry 10, 161 (2020)

37. Orlovska-Waast, S. et al. Cerebrospinal fluid markers of inflammation and infections in schizophrenia and affective disorders: a systematic review and meta-analysis. Mol. Psychiatry 24, 869-887 (2019).

38. Orlovska-Waast, S. et al. Correction: cerebrospinal fluid markers of inflammation and infections in schizophrenia and affective disorders: a systematic review and meta-analysis. Mol. Psychiatry 24, 929-934 (2019).

39. Schroeter, M. L. et al. Mood disorders are glial disorders: evidence from in vivo studies. Cardiovasc. Psychiatry Neurol. 2010, 780645 (2010).

40. Rajkowska, G. et al. Astrocyte pathology in the ventral prefrontal white matter in depression. J. Psychiatr. Res 102, 150-158 (2018).

41. Miguel-Hidalgo, J. J. et al. Glial and glutamatergic markers in depression, alcoholism, and their comorbidity. J. Affect Disord. 127, 230-240 (2010).

42. Rajkowska, G. \& Miguel-Hidalgo, J. J. Gliogenesis and glial pathology in depression. CNS Neurol. Disord. Drug Targets 6, 219-233 (2007).
43. Khundakar, A. A. \& Thomas, A. J. Morphometric changes in early- and late-life major depressive disorder: evidence from postmortem studies. Int. Psychogeriatr. 21, 844-854 (2009)

44. Paradise, M. B., Naismith, S. L., Norrie, L. M., Graeber, M. B. \& Hickie, I. B. The role of glia in late-life depression. Int. Psychogeriatr. 24, 1878-1890 (2012).

45. Holmström, U. et al. Cerebrospinal fluid levels of GFAP and pNF-H are elevated in patients with chronic spinal cord injury and neurological deterioration. Acta Neurochir. Wien.) 162, 2075-2086 (2020).

46. Banasr, M. et al. Glial pathology in an animal model of depression: reversal of stress-induced cellular, metabolic and behavioral deficits by the glutamatemodulating drug riluzole. Mol. Psychiatry 15, 501-511 (2010).

47. Kroksmark, H. \& Vinberg, M. Does S100B have a potential role in affective disorders? A literature review. Nord. J. Psychiatry 72, 462-470 (2018).

48. Pilzweger, C. \& Holdenrieder, S. Circulating HMGB1 and RAGE as clinical biomarkers in malignant and autoimmune diseases. Diagnostics (Basel) $\mathbf{5}$, 219-253 (2015).

49. Rong, $\mathrm{H}$. et al. Chronic mild stress induces fluoxetine-reversible decreases in hippocampal and cerebrospinal fluid levels of the neurotrophic factor S100B and its specific receptor. Int. J. Mol. Sci. 11, 5310-5322 (2010).

50. Kapural, M. et al. Serum S-100 $\beta$ as a possible marker of blood-brain barrier disruption. Brain Res. 940, 102-104 (2002).

51. Dantzer, R. Depression and inflammation: an intricate relationship. Biol. Psychiatry 71, 4-5 (2012).

52. Beurel, E., Toups, M. \& Nemeroff, C. B. The bidirectional relationship of depression and inflammation: double trouble. Neuron 107, 234-256 (2020).

53. Steiner, J. et al. S100B serum levels are closely correlated with body mass index: an important caveat in neuropsychiatric research. Psychoneuroendocrinology 35, 321-324 (2010).

54. Toscano, S. et al. An update on idiopathic intracranial hypertension in adults: a look at pathophysiology, diagnostic approach and management. J. Neurol. https://doi.org/10.1007/s00415-020-09943-9 (2020).

55. Rosenling, T. et al. The effect of preanalytical factors on stability of the proteome and selected metabolites in cerebrospinal fluid (CSF). J. Proteome Res. 8 , 5511-5522 (2009)

56. Simonsen, A. H. et al. Pre-analytical factors influencing the stability of cerebrospinal fluid proteins. J. Neurosci. Methods 215, 234-240 (2013).

57. Koel-Simmelink, M. J. A. et al. The impact of pre-analytical variables on the stability of neurofilament proteins in CSF, determined by a novel validated SinglePlex Luminex assay and ELISA. J. Immunol. Methods 402, 43-49 (2014).

58. Aurell, A., Rosengren, L. E., Wikkelsø, C., Nordberg, G. \& Haglid, K. G. The S-100 protein in cerebrospinal fluid: a simple ELISA method. J. Neurological Sci. 89 157-164 (1989).

59. Rosengren, L. E., Wikkelsø, C. \& Hagberg, L. A sensitive ELISA for glial fibrillary acidic protein: application in CSF of adults. J. Neurosci. Methods 51, 197-204 (1994).

60. Erickson, J. A. \& Grenache, D. G. Performance evaluation of a serum S-100B ELISA for use with cerebrospinal fluid. J. Appl. Lab. Med. 2, 811-813 (2018).

61. Zachrisson, O. C. et al. No evident neuronal damage after electroconvulsive therapy. Psychiatry Res. 96, 157-165 (2000).

62. Blennow, M., Sävman, K., Ilves, P., Thoresen, M. \& Rosengren, L. Brain-specific proteins in the cerebrospinal fluid of severely asphyxiated newborn infants. Acta Paediatr. 90, 1171-1175 (2001)

63. Steiner, J., Bielau, H., Bernstein, H.-G., Bogerts, B. \& Wunderlich, M. T. Increased cerebrospinal fluid and serum levels of S100B in first-onset schizophrenia are not related to a degenerative release of glial fibrillar acidic protein, myelin basic protein and neurone-specific enolase from glia or neurones. J. Neurol. Neurosurg. Psychiatry 77, 1284-1287 (2006).

64. Uher, T. \& Bob, P. Cerebrospinal fluid S100B levels reflect symptoms of depression in patients with non-inflammatory neurological disorders. Neurosci. Lett. 529, 139-143 (2012).

65. Grahn, A. et al. Cerebrospinal fluid biomarkers in patients with varicella-zoster virus CNS infections. J. Neurol. 260, 1813-1821 (2013).

66. Lauridsen, $C$. et al. Cerebrospinal fluid $A \beta 43$ is reduced in early-onset compared to late-onset Alzheimer's disease, but has similar diagnostic accuracy to Aß42. Front. Aging Neurosci. 9, 210 (2017).

67. Constantinescu, R. et al. Cerebrospinal fluid protein markers in PD patients after DBS-STN surgery-A retrospective analysis of patients that underwent surgery between 1993 and 2001. Clin. Neurol. Neurosurg. 174, 174-179 (2018).

68. Bårdsen, K. et al. Interleukin-1-related activity and hypocretin-1 in cerebrospinal fluid contribute to fatigue in primary Sjögren's syndrome. J. Neuroinflammation 16, 102 (2019). 
69. Constantinescu, R. et al. Cerebrospinal fluid biomarkers in patients with neurological symptoms but without neurological diseases. Acta Neurol. Scand. 140, 177-183 (2019).
70. Kleerekooper, I. et al. CSF levels of glutamine synthetase and GFAP to explore astrocytic damage in seronegative NMOSD. J. Neurol. Neurosurg. Psychiatry 91, 605-611 (2020). 